\title{
Comparative study of perceptions of family members to the end-of-life care in residential care facilities and hospitals in Tampere, Finland
}

\author{
Aino Lehmus ${ }^{1}$, Lauri Seinelä ${ }^{* 1,2,3,4}$, Jaakko Valvanne $e^{1,2,4,5}$ \\ ${ }^{1}$ School of Medicine, University of Tampere, Tampere, Finland \\ ${ }^{2}$ Purchaser for the Promotion for senior citizens welfare, City of Tampere, Tampere, Finland \\ ${ }^{3}$ Pirkanmaan erikoislääkäripalvelu Oy, Tampere, Finland \\ ${ }^{4}$ Gerontology Research Center (GEREC), Universities of Tampere and Jyväskylä, Tampere and Jyväskylä, Finland \\ ${ }^{5}$ Tampere University Hospital, Tampere, Finland
}

Received: May 21, 2015

DOI: $10.5430 /$ jha.v4n5p84
Accepted: July 9, 2015

Online Published: July 23, 2015

URL: http://dx.doi.org/10.5430/jha.v4n5p84

\begin{abstract}
Objective: Current trend in long-term care (LTC) is to bring the care to the place where the person lives and to avoid unnecessary transitions. The purpose of the study was to find out family members' opinions about the quality of end-of-life care in LTC compared to care in hospitals.

Methods: A postal questionnaire was sent to the family members of 168 residents, who had died during the year 2012 in LTC in Tampere, southern Finland.

Results: A total of 97 family members (58\%) returned the questionnaire. Eighty-two percent of the residents suffered from dementia. Family members seemed to be more satisfied with the care if the resident had died in LTC. Family members reported that residents who had died in LTC were more often kept clean $(80 \% v s .55 \% ; p=.020)$, their dignity was maintained more often ( $84 \%$ vs. $56 \% ; p=.021)$ and their wishes considering their care were acknowledged better $(82 \% v s .50 \% ; p=.033)$ compared to the residents that died in a hospital. Residents who died in LTC suffered also less from agitation (32\% vs. 60\%; $p=.047)$. The trend in the prevalence of other signs and symptoms and the prevalence of non-palliative interventions was lower, if the resident had died in LTC.

Conclusions: Family members perceived the quality of end-of-life care given in residential care facilities to be at least as good, or, in some cases, better than the quality of end-of-life care given in a hospital.
\end{abstract}

Key Words: End-of-life care, Family members, Perceptions, Long-term care facilities, Hospitals, Quality of care

\section{INTRODUCTION}

Only a few decades ago end-of-life care in Finland used to take place in hospitals. While the structure of health services has been changing in Finland in the $21^{\text {st }}$ century, the place where the end-of-life care is given has slowly shifted towards long-term care (LTC) facilities. The number of clients in LTC has increased about $41 \%$ in the $21^{\text {st }}$ century ${ }^{[1]}$ and the number of clients diagnosed with dementia has almost doubled between years 2001 and 2009. ${ }^{[2]}$ Today, the aim of LTC is not to transfer the person, but to bring the care to the place

\footnotetext{
*Correspondence: Lauri Seinelä; Email: lauri.seinela@uta.fi; Address: Jaakko Valvanne/Lauri Seinelä, Lääketieteen yksikkö, Lääkärinkatu 1, 33014 Tampereen yliopisto, Finland.
} 
where the person lives. Yet, there is only a little research on the quality of end-of-life care in LTC settings.

Despite these improvements most Finnish dementia patients still die in hospitals or health-care center wards (69\%), while $25 \%$ and $7 \%$ respectively die in LTC facilities and home. ${ }^{[3]}$ In the USA, about $66 \%$ of dementia patients die in LTC facilities. ${ }^{[4]}$

Transitions are common among the care facilities' residents ${ }^{[5]}$ although they interfere with the continuum of care, which again may lead to unnecessary treatments and complications, particularly in patients with severe dementia. ${ }^{[3,6,7]}$ The number of transitions increases with the proximity of death. ${ }^{[8]}$ Decisions not to hospitalize a resident are made only when the proximity of death is obvious. ${ }^{[6]}$ In Finland residents diagnosed with dementia have slightly fewer transitions than the residents without dementia. ${ }^{[8]}$ Transitions are associated with considerable individual burden and are rarely necessary, as the main goal in end-of-life care should be palliation according to both family members and nurses. ${ }^{[6,9]}$

Care facility residents' health and the ability to function often deteriorate slowly, and their dying process takes long, even years. ${ }^{[10]}$ That is why the share of palliative care should be already increased before death is imminent. However, people with advanced dementia are not often recognized as having a terminal condition and do not receive care that promotes palliation at the end of life. Instead they experience burdensome interventions. ${ }^{[11]}$ One study showed that during the 3 last months of life $30 \%$ of the residents with advanced dementia received parenteral therapy, $12 \%$ were hospitalized and $7 \%$ underwent tube feeding. ${ }^{[9]}$

The aim of end-of-life care should be the best possible quality of life. The American Medical Association ${ }^{[12]}$ has listed rights at the end of life and these include the detection and management of pain, autonomy, dignity, right to avoid burdensome and worthless interventions and right to receive information about one's health. Every patient should have the same rights regardless of cognitive status. The most common symptoms in the end of life are exhaustion, weight loss, pain, dyspnea, constipation, anxiety, and depression. Pain of a dying, elderly patient is often undertreated. ${ }^{[13,14]}$ Pain can be also a reason for restlessness and agitation among dementia patients. ${ }^{[15,16]}$ Many people with dementia suffer from distressing symptoms such as dyspnea (46.0\%), pain $(39.1 \%)$ and agitation (53.6\%). The proportion of people suffering from dyspnea and pain increases as the end of life approaches. ${ }^{[9]}$

The aim of this study was to investigate whether the quality of end-of-life care given in LTC facilities is at least as good

Published by Sciedu Press as the quality of end-of-life care given in hospitals, based on family members' assessment.

\section{MethodS}

In 2012, there were 48 LTC facilities in Tampere area (population base ca. 220,000 inhabitants). Each of the LTC facilities had 6-60 residents and overall they provided services for 690 people. In the same year, there were 168 deaths recorded. Twenty-three facilities provided data on at least one death $(n=1-16)$.

Information for this study was obtained by sending questionnaire to the family members of the deceased residents. The questionnaire was sent at the end of July 2013; the time between the resident's death and completing the questionnaire was from 7 to 19 months. The questionnaire was sent to the family member, who was named in the patient's medical files. Besides the actual questions it included background information of the respondent: the year of birth, gender, relationship to the resident, and the frequency of visits during the last month of resident's life.

Resident data collected from the medical files included date of birth and death, gender, and place of residence and death. Additionally another questionnaire was sent to the residential care facility and nurses were asked background information of the resident (the presence of dementia, the length of the stay in the facility, and transitions during the last month of resident's life).

Variables to the questionnaire were selected so that they were thought to represent important features of end-of-life care based on knowledge of the literature and clinical experience. ${ }^{[11,17-20]}$ Variables were organized into four main categories. The first category focused on the occurrence of burdensome interventions and advance care planning. Burdensome interventions included transitions, intravenous therapy or tube feeding and laboratory tests, during the last month of resident's life. The second category included questions about the prevalence of both physical and emotional signs and symptoms during the last month of the resident's life. The third category concerned the well-being of the resident. In the fourth category family members were asked several questions about their satisfaction with care. The final draft was circulated among geriatricians working in LTC, and edited based on the comments. The survey was approved by the city of Tampere in July 2013.

Findings were statistically analysed with SPSS 21.0. Descriptive statistics were conducted to all variables using frequencies for categorical variables and means with standard deviations for continuous variables. The answers of family members were divided into two categories depending on 
the place of death of the resident (LTC facility $v s$. hospital) and these subgroups were compared. Chi square tests were used to compare the answers on the basis of the place of death. If the chi square criteria were not fulfilled, Fishers exact test was used instead. The critical value for statistical significance was $p<.05$.

\section{RESULTS}

A total of 97 family members $(58 \%)$ returned the questionnaire. Residents whose family members did not return the questionnaire did not differ significantly in respect to age or gender from those who were used for the study. Nurses provided information about 132 residents out of which 80 responses were related to the same residents family members had provided data about. The information about the presence of dementia, the length of stay in the facility, and the number of transitions was reported for only these 80 residents.

The mean age of the residents, whose family member returned the questionnaire, was $88 \pm 6$ years. Out of these residents, $82 \%$ were female and $82 \%$ suffered from dementia. They were living in 21 different LTC facilities. There were 1-10 deaths per facility.

Most (80\%) of the family members were residents' immediate family (child or partner). The remaining were other relatives (18\%) and legal representatives (2\%). Family members' mean age was $65 \pm 10$ years, and $71 \%$ were female. Ninety-one percent of the family members visited the resident at least once a week during the last month of resident's life.

A total of $76(78 \%)$ of the residents died in a care facility and $21(22 \%)$ in a hospital. $29 \%$ of the residents who died in hospital had stayed less than a year in the same residential care facility whereas only $16 \%$ of the residents who died in the facility had lived there less than a year $(p=.291)$. Resi- dents who died in LTC or in hospital did not differ in terms of age, gender, or presence of dementia.

According to family members' evaluation, there was a lower prevalence of most signs and symptoms when the resident died in LTC compared to the situation where he/she died in a hospital (see Table 1). Residents who died in a hospital suffered more from agitation than those who died in LTC. There was a clear trend that other physical (e.g. pain, dyspnea) and emotional (e.g. fear, anxiety) symptoms were more frequent when the resident had died in a hospital but the results were not statistically significant.

Table 1. Family members' perspectives of symptoms and signs depending on the place of death $(n=97)$

\begin{tabular}{|c|c|c|c|c|}
\hline & $\mathbf{N}^{*}$ & & $\begin{array}{l}\text { re than } \\
\text { ek), \% }\end{array}$ & $p$-value \\
\hline & & $\mathrm{C}$ & $\mathbf{H}$ & \\
\hline Pain & 75 & 68 & 88 & .208 \\
\hline Dyspnea & 74 & 53 & 65 & .379 \\
\hline Swallowing problems & 73 & 52 & 60 & .567 \\
\hline Hypersalivation & 70 & 49 & 53 & .771 \\
\hline Pressure ulcers & 80 & 14 & 7 & .678 \\
\hline Depression & 56 & 33 & 55 & .298 \\
\hline Fear & 57 & 30 & 50 & .209 \\
\hline Anxiety & 63 & 35 & 50 & .298 \\
\hline Agitation & 74 & 32 & 60 & .047 \\
\hline Resistance to care & 67 & 16 & 17 & 1.000 \\
\hline
\end{tabular}

Note. $\mathrm{N}^{*}=$ number of the family members who answered the specific question; $\mathrm{C}=$ Care facility; $\mathrm{H}=$ Hospital

The well-being of the resident, as reported by a family member, varied significantly depending on the place of death as shown in Table 2. Residents that died in the care facility were more often kept clean, their dignity was maintained more often and their wishes in respect to their care were more often acknowledged compared to the residents that died in a hospital.

Table 2. Family members' perspectives of well-being of the resident depending on the place of death $(n=97)$

\begin{tabular}{|c|c|c|c|c|}
\hline & \multirow{2}{*}{$\mathbf{N}^{*}$} & \multicolumn{2}{|c|}{ Agree (\%) } & \multirow{2}{*}{ p-value } \\
\hline & & C & $\mathbf{H}$ & \\
\hline Resident was kept clean. & 96 & 80 & 55 & .020 \\
\hline Resident’s dignity was maintained. & 93 & 84 & 56 & .021 \\
\hline Residents religious needs were taken into account (e.g. he/she could see a priest if wanted). & 52 & 89 & 83 & .540 \\
\hline Resident had as much information as he/she wanted about his/her illness. & 68 & 84 & 62 & .122 \\
\hline $\begin{array}{l}\text { If resident had expressed his/her hopes regarding the end-of-life care beforehand, these were } \\
\text { honoured. }\end{array}$ & 63 & 82 & 50 & .033 \\
\hline Resident spent as much time as he/she wanted with his/her family. & 89 & 97 & 89 & .181 \\
\hline Resident and his/her family had privacy. & 92 & 99 & 89 & .107 \\
\hline
\end{tabular}

Note. $\mathrm{N}^{*}=$ number of the family members who answered the specific question; $\mathrm{C}=$ Care facility; $\mathrm{H}=$ Hospital 
Also the satisfaction with care varied depending on the place of death, although the difference was not statistically significant (see Table 3). More family members agreed with the statements concerning their satisfaction with care when the resident died in the care facility compared to the situation where the resident died in a hospital.

Table 3. Family members' satisfaction with care depending on the place of death $(n=97)$

\begin{tabular}{|c|c|c|c|c|}
\hline & \multirow{2}{*}{$\mathbf{N}^{*}$} & \multicolumn{2}{|c|}{ Agree (\%) } & \multirow{2}{*}{$p$-value } \\
\hline & & C & $\mathbf{H}$ & \\
\hline $\begin{array}{l}\text { 1. I felt fully involved in decision } \\
\text { making. }\end{array}$ & 93 & 81 & 72 & .515 \\
\hline $\begin{array}{l}\text { 2. I got enough information of } \\
\text { resident's condition. }\end{array}$ & 96 & 78 & 65 & .246 \\
\hline $\begin{array}{l}\text { 3. The health care team was } \\
\text { sensitive to my needs and feelings. }\end{array}$ & 93 & 80 & 67 & .227 \\
\hline $\begin{array}{l}\text { 4. All measures were taken to keep } \\
\text { the resident comfortable. }\end{array}$ & 95 & 73 & 60 & .245 \\
\hline $\begin{array}{l}\text { 5. I always knew which doctor or } \\
\text { nurse was in charge of the } \\
\text { resident's care. }\end{array}$ & 95 & 51 & 42 & .473 \\
\hline
\end{tabular}

The residents experienced several non-palliative interventions at their end of life. According to family members' reporting, $26 \%$ of the residents received intravenous therapy or had a feeding tube during their last month of life and $60 \%$ were subjected to laboratory tests. When comparing residents according to their place of death, all the interventions were more common if the person died in a hospital: intravenous therapy or tube feeding $(14 \%$ vs. $70 \% ; p<.001)$ and laboratory tests $(51 \%$ vs. $95 \%$; $p=.002)$.

According to nurses' reports, there was no difference in the occurrence of transitions (lasting at least one night) during the last month of life between the residents who were diagnosed with dementia and those who were cognitively intact (29\% vs. $36 \% ; p=.323)$. There also was no difference between the place of death depending on the cognitive status: $78 \%$ of the cognitively impaired and $79 \%$ of the cognitively intact residents died at the care facility $(p=1.000)$.

\section{DISCUSSION}

This study investigated the perspectives of family members related to end-of-life care in a LTC environment. To the best of our knowledge, it is the first of its kind in Finland. The study population was extensive including all those who died within the year 2012 in the residential care facilities in the Tampere area. The response rate was comparable with other similar studies $(58 \%)^{[21]}$ and can be considered satisfactory given the topic of the study and the delay between death and administration of the questionnaire.

Published by Sciedu Press
The well-being of the residents, as reported by family members, varied significantly depending on the place of death in favor of the care facilities. If the resident died in the care facility, family members were more inclined to agree with the statements that the resident was kept clean, his/her dignity was maintained, and his/her hopes regarding the end-of-life care were honored. Also the prevalence of non-palliative interventions was lower for residents who died in the facility. Furthermore the residents who died in the care facility suffered less from agitation. Our study showed that there was a clear trend that residents who died in care facilities also suffered less from other physical and emotional symptoms but the results were not statistically significant. Moreover, family members tended to be more satisfied with the care when the resident died in the care facility. Altogether, our results indicate that most family members were satisfied with the end-of-life care in residential care facilities.

Our results reinforce the results from the study made by Vohra et al. ${ }^{[22]}$ which stated that the place of death was significantly associated with satisfaction, family members being more satisfied with end-of-life care when their family member died in LTC facility as opposed to the hospital setting. Lack of sufficient communication was observed throughout the analysis. Over a fifth $(22 \%)$ of the family members whose next of kin died in the care facility thought they did not get enough information on the resident's condition. Only half $(51 \%)$ of the family members knew the doctor or nurse in charge of the resident's care. The low percentage was still obtained even though in Tampere every residential care client and their family members were asked to participate in a meeting with health care professionals after the resident moved to the facility. The high turnover of the workers and the fairly large number of substitutes in some facilities probably influenced the answers about knowing the nurse in charge. The high turnover rates have a negative impact on the residents, especially if they have dementia, and can result in behavioral triggers. ${ }^{[23]}$ Better and continual communication is therefore needed to improve the quality of care.

It is noteworthy that, according to family members' observation, the prevalence of pain, dyspnea, and swallowing problems among other distressing symptoms was considerably high in our study population. These symptoms are potentially treatable and more attention should be drawn to them. It is probable that residents who were hospitalized presented a higher symptom burden already before the hospitalization, which would explain the higher prevalence of most signs and symptoms when the resident died in a hospital. However, with our study design it is not possible to say if the difference was due to that or other factors. 
Our data showed that there was a significant difference in the number of non-palliative interventions during the last month of life depending on the place of death. This result confirms the previously known fact that hospitalized patients frequently experience uncomfortable interventions. ${ }^{[6]}$ It is probable that the residents who were hospitalized were previously in better condition and so had a better prognosis and therefore received more intensive care.

In some questions the response rates were small. This might be due to problems in evaluating the question, such as the prevalence of emotional signs and symptoms. Asking about religious needs might have been considered too private in Finnish cultural environment. It is also probable that family members did not answer a question if it did not have a personal significance for them or they thought it was unimportant for the resident. On the other hand, those who did answer, most likely found the question important.

This study has several limitations. As is true of any study, the results apply to a particular setting, and in this case, the Finnish environment. However, the results support the findings from other countries. ${ }^{[22]}$ Even though the study population was extensive, some subgroups became quite small in the analysis. There was a delay from 7 to 19 months between the time of death and the time the data were collected. The delay may have had an impact on how well the respondents remembered all the scenarios. Some background information was provided by nurses and because of the delay the reliability of the answers may have suffered. Selection bias is also possible: it is suggested that families may be more willing to participate in research if the teamwork has been harmonious. ${ }^{[24]}$ Another limitation of our study is that the reason for hospitalizing patients was not known.

The number of people with dementia and the need for residential care have been on the increase and will continue to rise. Many individuals with advanced dementia receive their end-of-life care in residential care facilities, which is the objective of LTC in Tampere. Therefore we found it important to evaluate the quality of the care in this environment.

In conclusion, family members observed that the quality of care was better when the end-of-life care was received in a residential care facility compared to care received in a hospital. Decisions related to hospitalization or transition should be carefully planned, and if possible, also discussed in advance. Yet it seems that when dying of a chronic, longlasting disease, it is better to end one's days in a familiar environment.

\section{ACKNOWLEDGEMENTS}

We express our gratitude to M.D. Ph.D. and fellow researcher Esa Jämsen who has contributed to the article by reading it through before submitting and giving valuable comments.

\section{REFERENCES}

[1] Tossavainen P, Kuronen R. Institutional care and housing services in social care 2011 [published in Finnish]; 2012. Report No.: 25.

[2] Vuorio S, Väyrynen R. Cognitively impaired clients in social and health services 2009 [published in Finnish]; 2011. Report No.: 12.

[3] Antikainen R, Konttila T, Virolainen J, et al. The end-of-life care of elderly people with advanced dementia [published in Finnish]. Finnish Med J. 2013; 68(12): 909-15.

[4] Mitchell SL, Teno JM, Miller SC, et al. A national study of the location of death for older persons with dementia. J Am Geriatr Soc. 2005; 53(2): 299-305. PMid: 15673356. http://dx.doi.org/10. $1111 / \mathrm{j} .1532-5415.2005 .53118 . \mathrm{x}$

[5] Forma L, Jylhä M, Aaltonen M, et al. The last years of life in old age. Long-term care and transitions between care facilities [published in finnish]; 2012. Report No.: 69.

[6] Lamberg JL, Person CJ, Kiely DK, et al. Decisions to hospitalize nursing home residents dying with advanced dementia. J Am Geriatr Soc. 2005; 53(8): 1396-401. PMid: 16078968. http: //dx.doi.org/10.1111/j.1532-5415.2005.53426.x

[7] Aaltonen M, Forma L, Rissanen P, et al. Transitions in health and social service system at the end of life. European Journal of Ageing. 2010; 7(2): 91-100. http://dx.doi.org/10.1007/s10433-010 $-0155-3$
[8] Aaltonen M, Rissanen P, Forma L, et al. The impact of dementia on care transitions during the last two years of life. Age \& Ageing. 2012; 41(1): 52-7. PMid: 22089082. http://dx.doi.org/10.1093/a geing/afr 133

[9] Mitchell SL, Teno JM, Kiely DK, et al. The clinical course of advanced dementia. N Engl J Med. 2009; 361(16): 1529-38. PMid: 19828530. http://dx.doi.org/10.1056/NEJMoa0902234

[10] Murray SA, Kendall M, Boyd K, et al. Illness trajectories and palliative care. BMJ. 2005; 330(7498): 1007-11. PMid: 15860828. http://dx.doi.org/10.1136/bmj.330.7498.1007

[11] Mitchell SL, Kiely DK, Hamel MB. Dying with advanced dementia in the nursing home. Arch Intern Med. 2004; 164(3): 321-6. PMid: 14769629. http://dx.doi.org/10.1001/archinte.16 4.3.321

[12] AMA statement on end-of-life care [online]. Available from: http://www . ama-assn.org/ama/pub/physician-resourc es/medical-ethics/about-ethics-group/ethics-resou rce-center/end-of-life-care/ama-statement-end-of-1 ife-care.page?

[13] Bernabei R, Gambassi G, Lapane K, et al. Management of pain in elderly patients with cancer. SAGE study group. systematic assessment of geriatric drug use via epidemiology. JAMA. 1998; 279(23): 1877-82. PMid: 9634258. http://dx.doi.org/10.1001/jama. 279.23 .1877 
[14] Morrison RS, Siu AL. A comparison of pain and its treatment in advanced dementia and cognitively intact patients with hip fracture. J Pain Symptom Manage. 2000; 19(4): 240-8. http://dx.doi.o rg/10.1016/S0885-3924(00)00113-5

[15] Manfredi PL, Breuer B, Wallenstein S, et al. Opioid treatment for agitation in patients with advanced dementia. Int J Geriatr Psychiatry. 2003; 18(8): 700-5. PMid: 12891637. http://dx.doi.org/10. 1002/gps. 906

[16] Husebo BS, Ballard C, Sandvik R, et al. Efficacy of treating pain to reduce behavioural disturbances in residents of nursing homes with dementia: Cluster randomised clinical trial. BMJ. 2011; 343: 4065. PMid: 21765198. http://dx.doi.org/10.1136/bmj.d4065

[17] Patrick DL, Engelberg RA, Curtis JR. Evaluating the quality of dying and death. Journal of Pain \& Symptom Management. 2001; 22(3): 717-26. http://dx.doi.org/10.1016/S0885-3924(01 ) 00333-5

[18] Volicer L, Hurley AC, Blasi ZV. Scales for evaluation of end-of-life care in dementia. Alzheimer Disease \& Associated Disorders. 2001; 15(4): 194-200. http://dx.doi.org/10.1097/00002093-200 110000-00005

[19] Engel SE, Kiely DK, Mitchell SL. Satisfaction with end-of-life care for nursing home residents with advanced dementia. J Am
Geriatr Soc. 2006; 54(10): 1567-72. PMid: 17038076. http: //dx.doi.org/10.1111/j.1532-5415.2006.00900.x

[20] Munn JC, Zimmerman S, Hanson LC, et al. Measuring the quality of dying in long-term care. J Am Geriatr Soc. 2007; 55(9): 1371-9. PMid: 17915342. http://dx.doi.org/10.1111/j.1532-5415. $2007.01293 . \mathrm{x}$

[21] Liu LM, Guarino AJ, Lopez RP. Family satisfaction with care provided by nurse practitioners to nursing home residents with dementia at the end of life. Clin Nurs Res. 2012; 21(3): 350-67. PMid: 22203088. http://dx.doi.org/10.1177/1054773811431883

[22] Vohra JU, Brazil K, Hanna S, et al. Family perceptions of end-of-life care in long-term care facilities. J Palliat Care. 2004; 20(4): 297-302. PMid: 15690832.

[23] Garcia LJ, Hebert M, Kozak J, et al. Perceptions of family and staff on the role of the environment in long-term care homes for people with dementia. International Psychogeriatrics. 2012; 24(5): 753-65. PMid: 22265186. http://dx.doi.org/10.1017/S1041610211 002675

[24] van der Steen JT, Deliens L, Ribbe MW, et al. Selection bias in family reports on end of life with dementia in nursing homes. J Palliat Med. 2012; 15(12): 1292-6. PMid: 23153076. http: //dx.doi.org/10.1089/jpm.2012.0136 